\title{
An inverse analysis to identify the Johnson-Cook constitutive model parameters for cold wire drawing process
}

\author{
Ashkan Mahmoud Aghdami ${ }^{1}$ and Behnam Davoodi ${ }^{2, *}$ \\ ${ }^{1}$ Department of Manufacturing Engineering, Faculty of Mechanical Engineering, University of Tabriz, Tabriz, Iran \\ ${ }^{2}$ School of Mechanical Engineering, Iran University of Science and Technology, Tehran, Iran
}

Received: 8 March 2020 / Accepted: 9 August 2020

\begin{abstract}
Johnson-Cook constitutive equation was utilized to model the 10100 copper and AA 1100 aluminum wires at the cold wire drawing process. Initial Johnson cook parameters were determined through quasi-static tensile tests at different strain rates. Analytical and finite element with VUHARD subroutine solutions were implemented to calculate the drawing forces using the Johnson cook parameters. Wire drawing experiments were carried out at different drawing conditions with two areal reductions and four drawing speeds with the strain rate ranged from $37 \mathrm{~s}^{-1}$ to $115 \mathrm{~s}^{-1}$ and wire drawing forces were measured using a load cell connected to the drawing die. Results showed that the Johnson cook model with parameters determined from a quasi-static condition was not able to predict the material behavior at the wire drawing process with a moderate strain rate. In order to modify the initial JC parameters an inverse analysis approach was adopted. An objective function was defined based on analytical and experimental drawing forces differences with respect to JC parameters. Using the Newton-Raphson method, new JC parameters were identified by minimizing the objective function. Updated Johnson cook parameters showed much more correlation with experimental results.
\end{abstract}

Keywords: Johnson-Cook / moderate strain rate / inverse analysis / wire drawing / constitutive equation

\section{Introduction}

The wire drawing process consists of reducing the crosssection of wires by forcing them through a series of dies. Most of the studies on the wire drawing process were focused on finding optimum process parameters using finite element methods or by experimental approach [1-4]. He et al. [5] studied the strain rate effect on the flow stress of carbon steel wires without mentioning the material model used. Among the numerous papers published in this field, there is not much work concerning the wire drawing as an intermediate strain rate process [6] to investigate the constitutive equations. Among the empirical or phenomenological based models, Johnson-Cook equation [7] is one of the primary constitutive models used widely for metals subjected to a large strain, high strain rate, and high temperature. This equation shows some deviation from experimental results because the original Johnson-Cook model assumes that thermal softening, strain rate hardening, and strain hardening are three independent phenomena and can be isolated from each other [8]. Chen [9] noted the coupling effect of the work hardening and strain rate for 7050-T7451 alloy and also coupled effect of thermal

\footnotetext{
* e-mail: bdavoodi@iust.ac.ir
}

softening and strain rate. Lin [10] expressed the JC parameters as a function of strain rate. In some researches, the strain rate coefficient value was considered as a function of strain and strain rate [11]. Vural [12] proposed a temperature-dependent equation for the strain hardening factor in the JC model. Some researchers adopt the same way of the decoupling of the three terms like the JC model and propose a new reasonably simple phenomenological constitutive model. Shins [13] proposed a model described the copper dynamic behavior in strain rates above $10^{4} \mathrm{~s}^{-1}$ well enough. Kang [14] modified the strain rate part of the JC model by changing the linear relation of the $\mathrm{C}$ parameter to a secondorder relation. Since the logarithmic function approaches minus infinity for minimal strain rates, Clausen [15] modified the strain rate hardening part.

Most of the studies on material models were based on results from laboratorial tests such as Hopkinson and Kolsky Bar apparatus [8,9,15-21], and fewer investigations were done based on real material forming processes. Optimization and inverse analysis approaches are also implemented on Johnson cook using machining forces and temperature. Machining forces and temperature in the shear zone were the key parameters of Ning [22,23] study to modify the JC parameters. Initial JC parameters were acquired from literature. Ning et al. inverse approach was to change the initial JC parameters up to $50 \%$ of their 
Table 1. Chemical composition of copper and aluminum wires.

\begin{tabular}{llllll}
\hline Copper wire & $\mathrm{Cu}(\mathrm{wt} \%)$ & $\mathrm{Pb}(\mathrm{wt} \%)$ & $\mathrm{Zn}(\mathrm{wt} \%)$ & $\mathrm{P}(\mathrm{wt} \%)$ & $\mathrm{O}(\mathrm{wt} \%)$ \\
& $99.99 \%$ & $0.0005 \%$ & $0.0001 \%$ & $0.0003 \%$ & $0.0005 \%$ \\
\hline \multirow{2}{*}{ Aluminum wire } & $\mathrm{Al} \mathrm{(wt \% )}$ & $\mathrm{Cu}(\mathrm{wt} \%)$ & $\mathrm{Mn}(\mathrm{wt} \%)$ & $\mathrm{Si}(\mathrm{wt} \%)$ & $\mathrm{Fe}(\mathrm{wt} \%)$ \\
& $99.98 \%$ & $0.001 \%$ & $0.001 \%$ & $0.046 \%$ & $0.121 \%$ \\
\hline
\end{tabular}

reference values to reach the minimum difference in experimental and FE simulation of machining force and temperature. He did not mention any formulation to specify the changing factor of JC parameters. A similar approach was used by Agmell [24] to identify the model constants inversely by using the Kalman filter technique. In this technique an iterative approach was adopted to find the five JC parameters. Inversely calculated JC model parameters from different studies were also compared by Laakso [25]. Friction stir welding was another tool used by Grujicic [26] to adopt the inverse analysis. Faurholdt [27] used in deep drawing process as a large strain method to inversely calculate the JC constants. He used the Levenberg-Marquardt method to minimize the objective function. Szeliga et al. [28] used uniaxial compression, ring compression, cube compression, plane strain compression and channel test to inversely define the Zener-Hollomon parameters. The results of his study showed that the identification are insensitive to the type of the test. Another technique to inversely define the material's properties is to use indenter tools with different tip angles [29-31]. This method mostly is used to determine the elastic properties and hardening coefficient but not the strain rate related parameters $[32,33]$.

In the present work, Johnson cook parameters were determined from quasi-static tensile tests. Same procedure was carried out in literature [17]. These parameters were used to simulate the wire drawing process at seven different reductions and drawing speeds. The difference between drawing forces from experimental and simulation showed that the JC parameters from lower strain rate condition could not be able to predict material behavior in moderate strain rate condition. Similar results was reported at Lin [34] and a modified JC model was developed. Hence an inverse analysis was implemented to modify the constants. Simulation with new parameters showed a better correlation with experimental results.

\section{Material}

Electronic copper C10100 wire with the chemical composition shown in Table 1 was used in this research. Chemical analysis was done using the Atomic Emission Spectroscopy. To remove the cold work effects from former drawing processes, copper and aluminum wires were annealed at $500{ }^{\circ} \mathrm{C}$ and $300{ }^{\circ} \mathrm{C}$ respectively for one hour and before using.

All specimens were cut in one-meter length. One end of wires was grinded to reduce the diameter to initial pass of wire through the drawing die.

\subsection{Quasi-static tensile test}

Quasi-static tensile tests were performed on specimens using the SANTAM STM-400 universal testing machine.

Wires with a gauge length of $145 \mathrm{~mm}$ and initial diameter of $3.52 \mathrm{~mm}$ and $3.72 \mathrm{~mm}$ for copper and aluminum alloys were fixed on the tensile machine. The test speed was $15 \mathrm{~mm} / \mathrm{min}$ for copper wire and $5 \mathrm{~mm} / \mathrm{min}$ for aluminum wire. The extensometer was used to accurately read the strain to determine the Young's modulus and yield stress. True stress- True strain of copper and aluminum wires is shown in Figure 1.

Using the $0.2 \%$ offset yield strength method, the yield strength for copper and aluminum wires calculated as $150 \mathrm{MPa}$ and $83 \mathrm{MPa}$ and the Young's modulus become $115 \mathrm{GPa}$ and $70 \mathrm{GPa}$ respectively. The reference strain rate acquired from the quasi-static test for copper wires was $1.28 \times 10^{-3} \mathrm{~s}^{-1}$ and for aluminum wires was $7.8 \times 10^{-4} \mathrm{~s}^{-1}$.

\section{Johnson-Cook model}

This model is appropriate for describing the stress and strain relations of metallic materials under conditions of large deformation, high strain rate, and high temperature. Due to the simple form, it has been widely used soon after it was proposed. The model was expressed as follows [7]:

$$
\sigma=\left(A+B \varepsilon^{n}\right)\left(1+C \ln \dot{\varepsilon}^{*}\right)\left(1-\left(T^{*}\right)^{m}\right)
$$

where $\sigma$ is the equivalent stress, $\varepsilon$ is the equivalent plastic strain, $\dot{\varepsilon}^{*}=\dot{\varepsilon} / \dot{\varepsilon}_{0}, \dot{\varepsilon}_{0}$ is the reference strain rate. $T^{*}=(T-$ $\left.T_{r}\right) /\left(T_{m}-T_{r}\right)$ where, $T_{r}$ is the room temperature, $T_{m}$ is the melting point of the material. $A$ is the yield stress at the room temperature and reference strain rate, $B$ is the coefficient of strain hardening, $\mathrm{n}$ is the strain hardening exponent, $C$ and $m$ are the material constants relate to strain rate hardening and thermal softening.

\subsection{Determination of work hardening parameters}

Considering the plastic part of the stress-strain curve, the work hardening parameters $A, B$, and $n$ can be determined using the curve fitting method. When $\dot{\varepsilon}=\dot{\varepsilon}_{0}$ and at room temperature the equation (1) would become:

$$
\sigma=\left(A+B \varepsilon^{n}\right) .
$$

The $A, B$ and $n$ were determined using the stress-strain curve from quasi-static tests. 

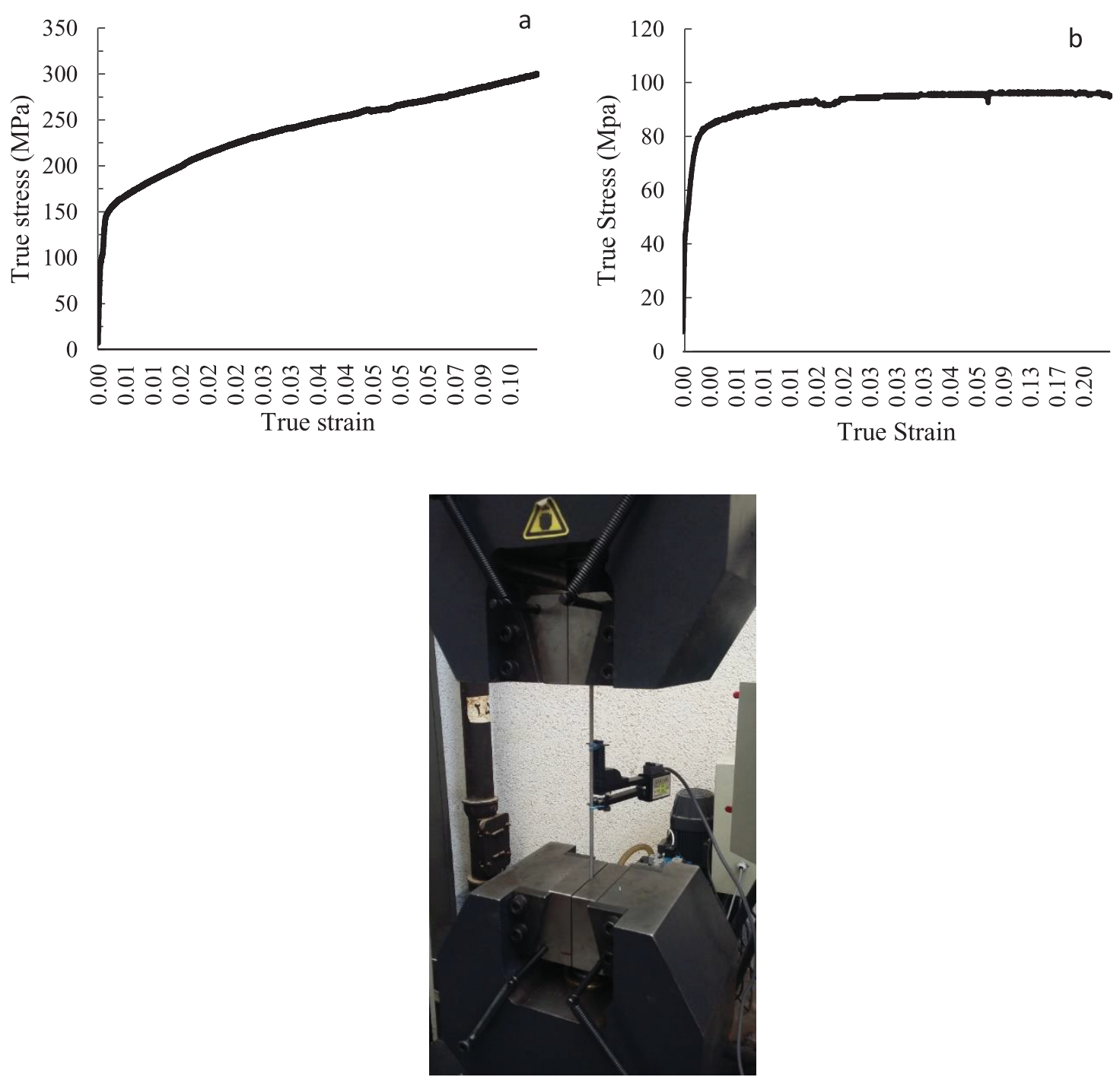

Fig. 1. True stress-true strain curve of (a) copper 10100 and (b) aluminum wires at the quasi-static test.

Table 2. Strain rates carried out for tensile tests.

\begin{tabular}{llllll}
\hline & $\dot{\varepsilon}_{1}\left(\mathrm{~s}^{-1}\right)$ & $\dot{\varepsilon}_{2}\left(\mathrm{~s}^{-1}\right)$ & $\dot{\varepsilon}_{3}\left(\mathrm{~s}^{-1}\right)$ & $\dot{\varepsilon}_{4}\left(\mathrm{~s}^{-1}\right)$ & $\dot{\varepsilon}_{5}\left(\mathrm{~s}^{-1}\right)$ \\
\hline Copper wire & $2.66 \times 10^{-3}$ & $6.38 \times 10^{-3}$ & $3.4 \times 10^{-2}$ & 0.45 & 1.1 \\
Alumimum wire & $7.81 \times 10^{-3}$ & $1.78 \times 10^{-2}$ & $2.6 \times 10^{-2}$ & 0.6 & 1.02 \\
\hline
\end{tabular}

\subsection{Determination of strain rate coefficient}

After calculating the work hardening parameters, the JC model can be written as follows at room temperature:

$$
\frac{\sigma}{A+B \varepsilon^{n}}=1+C \ln \dot{\varepsilon}^{*} .
$$

Parameter $C$ is the strain rate sensitivity factor of a material. To determine this parameter, the tensile tests in the previous section were carried out at different strain rates mentioned in Table 2.
According to the equation (3), the parameter $C$ is the slope of the linear relation between $\sigma /\left(A+B \varepsilon^{n}\right)$ and strain rate in different strains. This relation is shown in Figure 2.

Temperature rise in wire drawing depends on drawing speed and areal reduction. Haddi et al. [2] studied wire temperature rise in copper wires at different wire drawing conditions. He showed that there is a linear relation between the wire temperature rise and drawing ratio. For maximum drawing ratio the ratio of inlet and outlet wire temperature is 2.3 . Taking $25{ }^{\circ} \mathrm{C}$ as initial temperature of wires, the maximum wire temperature at die deformation 

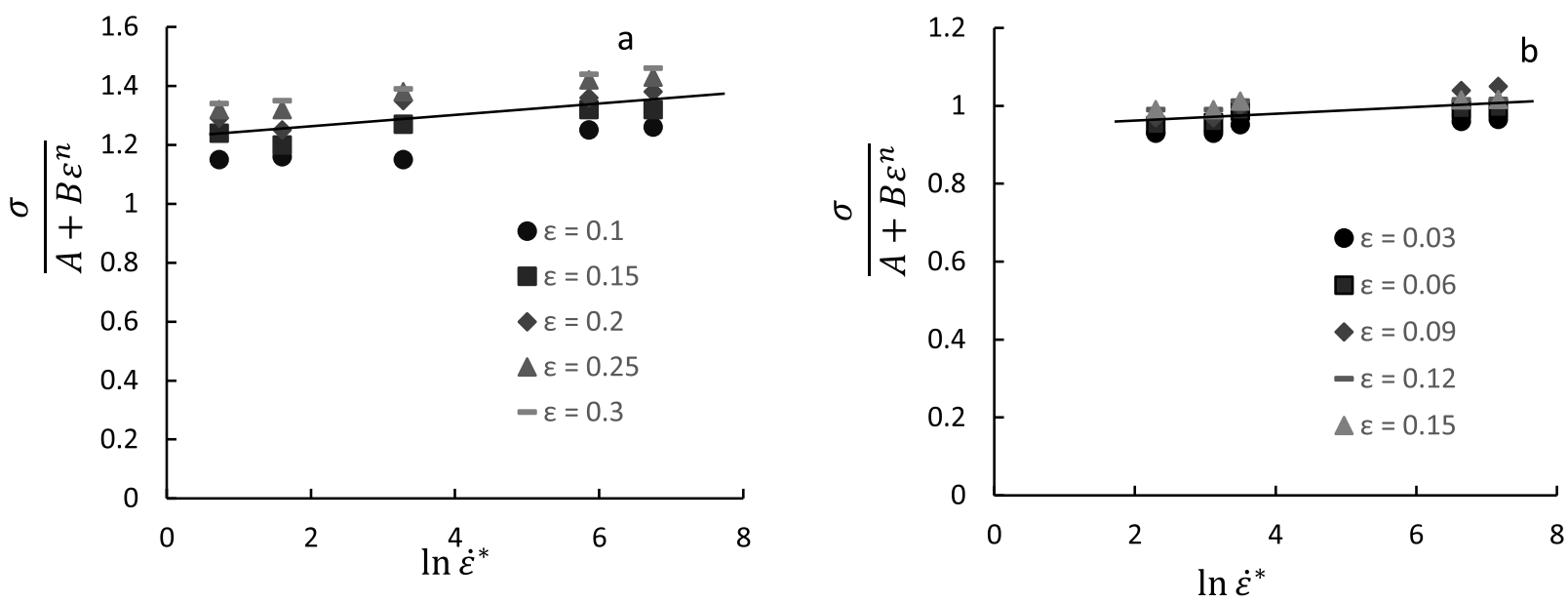

Fig. 2. $\frac{\sigma}{A+B \varepsilon^{n}}$ vs. $\ln \dot{\varepsilon}^{*}$ at different strains to find parameter C for (a) copper and (b) aluminum wire.

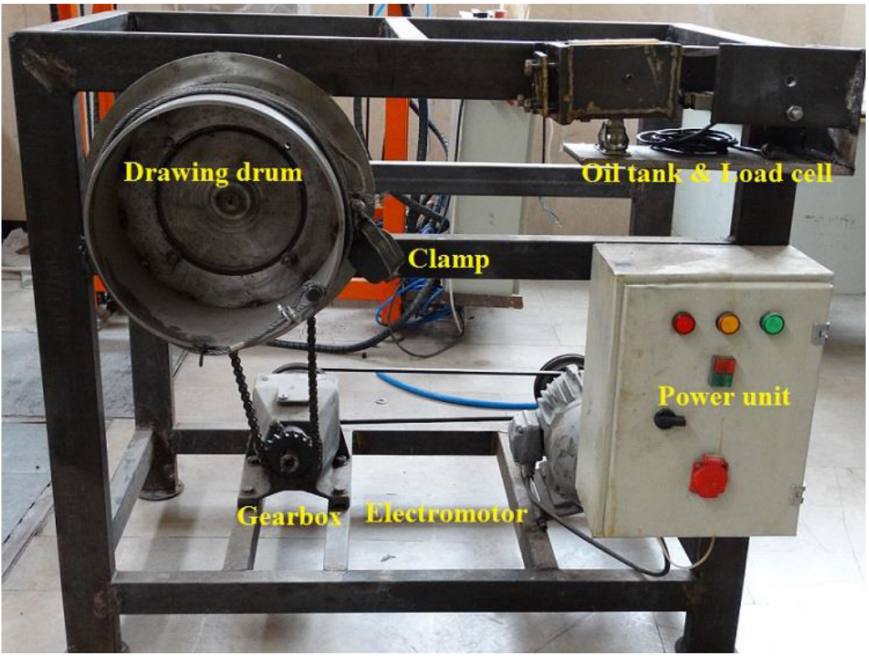

Fig. 3. Wire drawing machine used.

zone would be $57^{\circ} \mathrm{C}$. This temperature in copper cannot lead to much temperature softening. For this reason there was no direct attempt to calculate the m parameter of JC model in present work and its initial value was taken from the literature which is $1.09[7,35]$ and 1.13 [36] for copper and aluminum wire respectively. The melting point of copper and aluminum wire was considered as $1083{ }^{\circ} \mathrm{C}$ [37] and $650{ }^{\circ} \mathrm{C}[38]$ respectively.

So the JC parameters for copper wires were calculated as follows:

\section{Experiments}

\subsection{Machine}

The wire drawing machine used in this article is shown in Figure 3. The machine is driving with a $3 \mathrm{Hp}$ electromotor connected to a gearbox. Using an inverter, the rotational speed of the drawing drum was changed to achieve the desire drawing speeds.
The drawing die was fixed on a lubrication tank, which is connected to the machine body using a bar end joint. There are two rollers under the lubricating tank holding the tank weight and also letting it rotate freely about the bar joint. A load cell was fitted between the lubricating tank and the bar joint so that the drawing force along the wire will be sensed by the load cell. This setup would let the lubricating box and the load cell to align with drawing direction so all the drawing forces in any direction would be sensed by the load cell. Figure 4 shows the die and load cell connection.

\subsection{Wire drawing tests}

The drawing experiments were done at four different drawing speeds and two area reductions. Drawing speeds were set using an inverter connected to the electromotor. Two tungsten carbide dies with the outer diameter of $3.3 \mathrm{~mm}$, and $3.1 \mathrm{~mm}$ were used. The engineering strain rate for each test condition was calculated through equation (4)

$$
\dot{\varepsilon}=\frac{2 \ln \left(D_{0} / D_{1}\right)}{l / v}
$$

In this equation, $D_{0}$ isthe initial wire diameter, $D_{1}$ is the die exit diameter, $l$ is the length of the deformation zone, and $V$ is the pulling speed. Experiments were done for seven and three testing conditions for copper and aluminum wires as shown in Table 4 .

Note that drawing speed of $800 \mathrm{~mm} / \mathrm{s}$ at $22 \%$ reduction for copper and aluminum, caused the wires to break.

\section{Analytical solution}

The wire drawing process was analyzed through analytical calculation, and the drawing forces obtained for the drawing conditions is mentioned in Table 3. Final drawing stress including uniform work, redundant work, and 

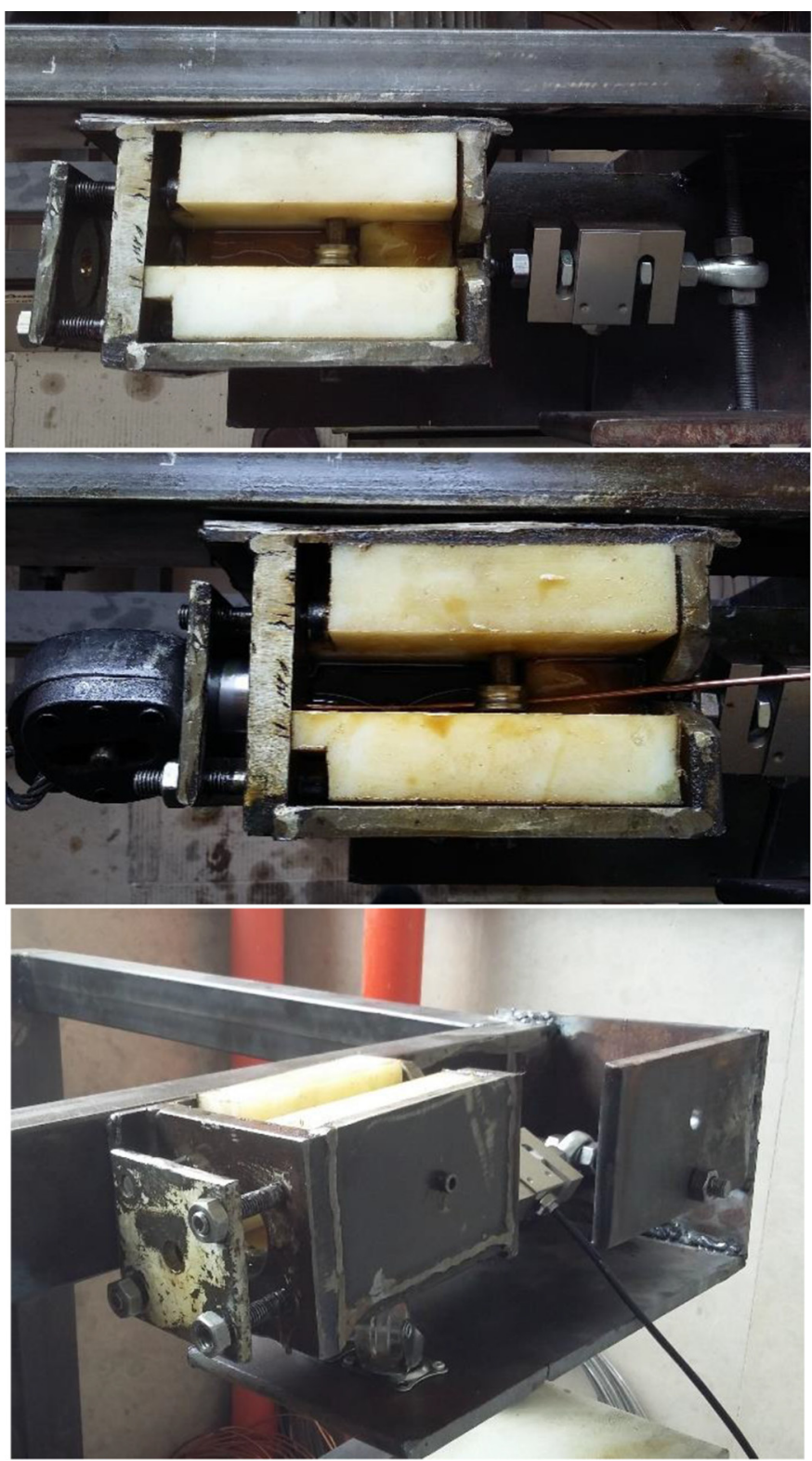

Fig. 4. Lubricating tank and load cell connection.

friction work is as follows [39]:

$$
\sigma_{d}=\sigma(\ln [1 /(1-r)]+(\varphi-1) \ln [1 /(1-r)]+4 \mu \varphi / \Delta) .
$$

In equation (5), $\sigma_{d}$ is the drawing stress of the wire, $\sigma$ is the flow stress of the wire, $r$ is the wire areal reduction. $\varphi$ is
Table 3. JC parameters for copper and aluminum using quasi-static tensile tests.

\begin{tabular}{lcclll}
\hline & $A(\mathrm{MPa})$ & $B(\mathrm{MPa})$ & $n$ & $C$ & $m$ \\
\hline Copper wire & 150 & 227 & 0.69 & 0.017 & 1.09 \\
Aluminum wire & 83 & 65 & 0.44 & 0.018 & 1.13 \\
\hline
\end{tabular}

the redundant factor which for typical drawing leads to [39]:

$$
\varphi=0.8+\Delta / 4.4
$$

Approximate value for $\Delta$ can calculated as:

$$
\Delta=4 \tan \alpha / \ln [1 /(1-r)]
$$

$\alpha$ is the die semi angle and is equal to 0.157 radian in present work. Combining equations and (7) into the equation (5) and assuming $\tan \alpha \approx \alpha$, the equation (5) would become: (6)

$$
\sigma_{d}=\sigma[(3.2 / \Delta)+0.9](\alpha+\mu)
$$

Multiplying equation (8) into exit wire cross area would result in drawing force:

$$
F_{\text {ana }}=\pi / 4 D_{1}^{2} \sigma[(3.2 / \Delta)+0.9](\alpha+\mu)
$$

$\sigma$ was considered as the average of the flow stress of entering $\left(\sigma_{0}\right)$ and exiting $\left(\sigma_{1}\right)$ wire which means $\sigma=\left(\sigma_{0}+\right.$ $\left.\sigma_{1}\right) / 2$. As mentioned before, all wires were annealed before entering the die, so $\sigma_{a 0}$ would be equal to wire yield stress, which is $150 \mathrm{MPa}$. In this case $\sigma_{1}$ would be the JC flow stress. So the $\sigma$. can be rewritten as:

$$
\sigma=1 / 2\left(\sigma_{y}+\left(A+B \varepsilon^{n}\right)\left(1+C \ln \dot{\varepsilon}^{*}\right)\right) .
$$

Substituting the equation (10) into the equation (9) gives the drawing force

$$
\begin{aligned}
F_{\text {ana }}= & \pi / 8 D_{1}^{2}\left(\sigma_{y}+\left(A+B \varepsilon^{n}\right)\left(1+C \ln \dot{\varepsilon}^{*}\right)\right) \\
& \times[(3.2 / \Delta)+0.9](\alpha+\mu) .
\end{aligned}
$$

\subsection{Coefficient of friction}

Avitzur and Evans [40,41] model is widely used in literature.

See equation (12) below.

$$
\frac{\sigma_{d}}{\sigma}=\frac{\left[\frac{\sigma_{b}}{\sigma}+2 f(\alpha) \ln \left(\frac{D_{0}}{D_{1}}\right)+\frac{2}{\sqrt{ } 3}\left(\frac{\alpha}{\sin ^{2} \alpha}-\cot \alpha\right)+2 \mu\left(\cot \alpha\left(1-\frac{\sigma_{b}}{\sigma}-\ln \left(\frac{D_{0}}{D_{1}}\right)\right)\right) \ln \left(\frac{D_{0}}{D_{1}}\right)+\frac{2 P}{D_{1}}\right]}{\left[1+2 \mu \frac{2 P}{D_{1}}\right]}
$$


Table 4. Experimental wire drawing conditions for copper and aluminum wires.

\begin{tabular}{|c|c|c|c|c|c|}
\hline & $D_{0}(\mathrm{~mm})$ & $D_{1}(\mathrm{~mm})$ & $r(\%)$ & $V(\mathrm{~mm} / \mathrm{s})$ & $\dot{\varepsilon}\left(\mathrm{s}^{-1}\right)$ \\
\hline \multirow{8}{*}{ Copper wire } & \multirow{5}{*}{3.52} & \multirow{5}{*}{3.3} & \multirow{5}{*}{12} & 200 & 37 \\
\hline & & & & 400 & 75 \\
\hline & & & & 600 & 112 \\
\hline & & & & 800 & 150 \\
\hline & & & & 200 & 38 \\
\hline & \multirow[t]{3}{*}{3.52} & \multirow[t]{3}{*}{3.1} & \multirow[t]{3}{*}{22} & 400 & 77 \\
\hline & & & & 600 & 115 \\
\hline & & & & 200 & 36 \\
\hline \multirow[t]{2}{*}{ Aluminum wire } & \multirow[t]{2}{*}{3.72} & \multirow[t]{2}{*}{3.3} & \multirow[t]{2}{*}{21} & 400 & 72 \\
\hline & & & & 600 & 108 \\
\hline
\end{tabular}

Table 5. Coefficient of friction for drawing conditions.

\begin{tabular}{|c|c|c|c|c|c|c|}
\hline & $D_{0}(\mathrm{~mm})$ & $D_{1}(\mathrm{~mm})$ & $\mathrm{V}(\mathrm{mm} / \mathrm{s})$ & $\dot{\varepsilon}\left(s^{-1}\right)$ & $\sigma_{d}(\mathrm{MPa})$ & $\mu$ \\
\hline \multirow{8}{*}{ Copper wires } & \multirow{5}{*}{3.52} & \multirow{5}{*}{3.3} & 200 & 37 & 86 & 0.086 \\
\hline & & & 400 & 75 & 84.9 & 0.078 \\
\hline & & & 600 & 112 & 83 & 0.069 \\
\hline & & & 800 & 150 & 82.7 & 0.061 \\
\hline & & & 200 & 38 & 130 & 0.049 \\
\hline & \multirow[t]{3}{*}{3.52} & \multirow[t]{3}{*}{3.1} & 400 & 77 & 129.8 & 0.046 \\
\hline & & & 600 & 115 & 129.7 & 0.044 \\
\hline & & & 200 & 36 & 57.3 & 0.060 \\
\hline \multirow[t]{2}{*}{ Aluminum wires } & \multirow[t]{2}{*}{3.72} & \multirow[t]{2}{*}{3.3} & 400 & 72 & 55.09 & 0.050 \\
\hline & & & 600 & 108 & 54.98 & 0.040 \\
\hline
\end{tabular}

$$
\begin{aligned}
f(\alpha)= & \frac{1}{\sin ^{2} \alpha}\left\{1(\cos \alpha) \sqrt{1 \frac{11}{12} \sin ^{2} \alpha}\right. \\
& \left.+\frac{1}{\sqrt{11.12}} \ln \frac{1+\sqrt{\frac{11}{12}}}{\sqrt{\frac{11}{12} \cos \alpha}+\sqrt{1 \frac{11}{12} \sin ^{2} \alpha}}\right\} .
\end{aligned}
$$

In this equation $\alpha$ is the die semi angle, $\sigma_{d}$ is drawing stress which is equal to experimental drawing force / exit wire area, $\sigma$ is the flow stress of wire, $D_{0}$ is initial wire diameter, $D_{1}$ is wire diameter at die exit, $\frac{\sigma_{b}}{\sigma}$ is relative back stress, $P$ is the d land length. In equation $(15), f(\alpha)$ is 1.00052. According to the avitzur model, the coefficients of friction for experimental drawing conditions in this study are mentioned in Table 5 .

As is seen in Table 5, by increasing the drawing speed and strain rate, the drawing sess and relative coefficient of friction were reduced.

\section{FEM analysis}

The JC parameters acquired from quasi-static tests and coefficient of friction from the previous section were used to simulate the cold copper wire drawing process at different drawing conditions mentioned in Table 4, and the drawing forces were generated.

The FEM simulation was done in the ABAQUS commercial code. The wire drawing process was modeled as 2D axisymmetric in explicit dynamic mode. The standard dynamic temperature coupled element (CAX4RT) was used to solve the problem. The number of elements in wire section is 1989 and the elements size is $0.1 \mathrm{~mm}$. For die section the number of elements is 32 and the size is $1 \mathrm{~mm}$. An isotropic mechanical contact was defined between adjacent wire and die surface with penalty friction formulation with coefficient of friction stated in Table 5. The FE model is shown in Figure 5. The JC parameters calculated from quasi-static tests were put as the material model in software. The die was considered as tungsten-carbide material, and the die angle was set to 9 degrees. The ambient temperature was set to $25^{\circ} \mathrm{C}$, and 
Table 6. Physical and mechanical properties of wires and die material $[37,42]$.

\begin{tabular}{lccclcc}
\hline & $\begin{array}{l}\text { Conductivity } \\
(\mathrm{W} / \mathrm{mK})\end{array}$ & $\begin{array}{l}\text { Density } \\
\left(\mathrm{kg} / \mathrm{m}^{3}\right)\end{array}$ & $\begin{array}{l}\text { Young } \\
\text { modules } \\
(\mathrm{GPa})\end{array}$ & $\begin{array}{l}\text { Poisson } \\
\text { ratio }\end{array}$ & $\begin{array}{l}\text { Expansion } \\
\text { coefficient }\left(\mathrm{K}^{-1}\right)\end{array}$ & $\begin{array}{l}\text { Specific } \\
\text { heat } \\
(\mathrm{J} / \mathrm{kgK})\end{array}$ \\
\hline Aluminium & 167 & 2700 & 70 & 0.3 & $2.4 \times 10^{-5}$ & 900 \\
Copper & 391 & 8900 & 115 & 0.3 & $1.7 \times 10^{-5}$ & 384 \\
Tungestan- Carbide & 84 & 14900 & 614 & 0.25 & $5.2 \times 10^{-6}$ & 210 \\
\hline
\end{tabular}

Table 7. Average drawing force from experimental and simulation results and analytical solution with JC parameters determined from the quasi-static tensile test.

\begin{tabular}{|c|c|c|c|c|c|c|c|c|}
\hline & $D_{0}(\mathrm{~mm})$ & $D_{1}(\mathrm{~mm})$ & $V(\mathrm{~mm} / \mathrm{s})$ & $\dot{\varepsilon}\left(\mathrm{s}^{-1}\right)$ & $F_{\exp }$ & $F_{a n a}$ & $F_{\text {sim }}$ & Error $=\frac{F_{\exp }-F_{\text {sim }}}{F_{\exp }} \times 100$ \\
\hline \multirow{8}{*}{ Copper wires } & \multirow{5}{*}{3.52} & \multirow{5}{*}{3.3} & 200 & 37 & 696 & 630 & 622 & 10.6 \\
\hline & & & 400 & 75 & 697 & 613 & 615 & 11.7 \\
\hline & & & 600 & 112 & 698 & 592 & 609 & 12.7 \\
\hline & & & 800 & 150 & 686 & 573 & 578 & 15.7 \\
\hline & & & 200 & 38 & 925 & 729 & 740 & 20 \\
\hline & \multirow[t]{3}{*}{3.52} & \multirow[t]{3}{*}{3.1} & 400 & 77 & 951 & 730 & 743 & 21.8 \\
\hline & & & 600 & 115 & 956 & 732 & 751 & 21.4 \\
\hline & & & 200 & 36 & 490 & 435 & 454 & 7.34 \\
\hline \multirow[t]{2}{*}{ Aluminum wires } & \multirow[t]{2}{*}{3.72} & \multirow[t]{2}{*}{3.3} & 400 & 72 & 471 & 427 & 443 & 5.94 \\
\hline & & & 600 & 108 & 470 & 418 & 427 & 9.14 \\
\hline
\end{tabular}

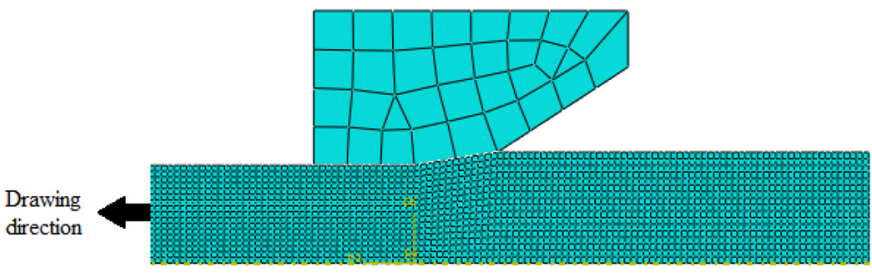

Fig. 5. FEM model used to simulate the wire drawing process.

the convection coefficient of air around was set to $15 \mathrm{~W} / \mathrm{m}^{2} \mathrm{~K}$ for the boundary condition. The physical and mechanical properties of die and wires are listed in Table 6 . The die was fixed in both directions on one nod on the die, and drawing direction was from right to left, and the reaction force on fixed nod along pulling direction considered as drawing force. To solve the problem in the plastic region and to introduce the $\mathrm{JC}$ constitutive model to the FEM model, a VUHARD subroutine was developed. The JC model and its derivatives with respect to strain and strain rate and constitutive parameters were included in the subroutine.

\section{Results}

Average drawing forces from experimental tests, analytical solution, and FEM simulation are presented and compared in seven different drawing conditions in Table 7 and Figure 6 .
Simulation and analytical results are considerably close to each other, and it somehow verifies the simulation procedure.

Looking at error amounts between the experimental and simulation results in Table 7 shows that in both wire materials, the error amount gets higher as the strain rate increases. The number of error in lower drawing speeds is smaller compare to higher drawing speeds because in lower drawing speeds, the strain rate in wire drawing is close to quasi-static strain rate condition in which the JC parameters where determined. By extending the strain rates to higher values, the error increases. This is one of the primary deficiencies of the JC model, which confines it to specific strain rates, and parameters have to be updated as the deformation conditions change.

In the wire drawing process, two phenomena have the opposite effect on drawing force. As the drawing speed and the strain rate elevates, the flow stress of wires increases due to the JC constitutive relation. On the other hand, friction decreases as the drawing speed increases. At copper wire drawing with $3.3 \mathrm{~mm}$ die, the lubrication condition changed from almost boundary type lubrication $(\mu=0.086)$ to near thick film lubrication $(\mu=0.061)$ [39]. So the strain rate and the friction are in close competition to control the drawing force and resulted in almost constant drawing force with drawing speed changes. But at drawing with $3.1 \mathrm{~mm}$ die, lubrication performance was better, and the coefficient of friction was at its minimum value of $\mu=0.04$. So by increasing the drawing 

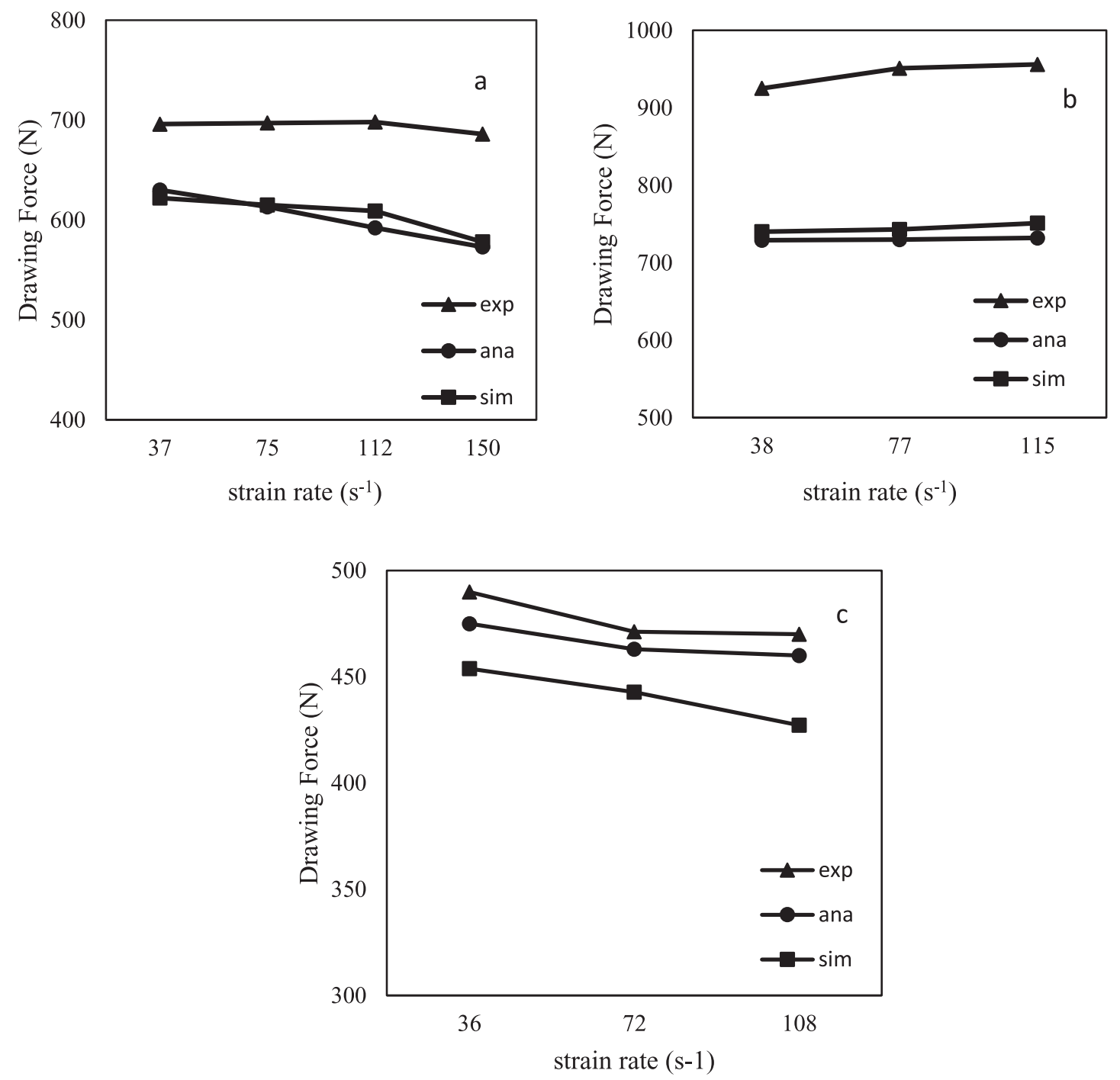

Fig. 6. Drawing force from experimental, analytical solution and FEM simulation with JC parameters determined from the quasistatic tensile test for copper wire with output (a) diameter of $3.3 \mathrm{~mm}$ and (b) diameter of $3.1 \mathrm{~mm}$ and (c) aluminum wire with output diameter of $3.3 \mathrm{~mm}$.

speed and the strain rate, the friction force did not change, but the flow stress increased due to the JC equation and caused the drawing force to grow as well. Aluminum is not so sensitive to strain rate changes especially in lower temperatures $[17,43,44]$. So the friction plays the main role ctrolling the drawing force in aluminum wire drawing and decrease dramatically as the drawing speed gets higher.

\section{Inverse analysis}

To update the JC parameters, an inverse method was used [45]. An objective function in a least square sense was defined as equation (14):

$$
E\left(p_{k}\right)=\frac{1}{N} \sum_{i=1}^{N}\left(\frac{F_{\exp }-F_{a n a}\left(p_{k}\right)}{F_{\exp }}\right)^{2} .
$$

where $N$ is the number of sampling points in drawing force vs. time curve, $p_{k}$ are the JC equation parameters. When the $E\left(p_{k}\right)$. is minimized, the JC parameters were determined. The $F_{a n a}$. was obtained from $F_{s i m}$. For given JC parameters $p_{k}$, the objective function will be minimum at:

$$
\frac{\partial E\left(p_{k}\right)}{\partial p_{k}}=0 \quad k=1,2, \ldots, q
$$

$q$ is the number of rheological parameters of the JC model which are involved in the inverse analysis.

The first prentices of the JC model (Eq. (1)) is related to the plastic region of the material. This part can be determined through the quasi-static test, which was presented in Section 2.1. So the parameters A, B, and n were remained uhanged during the inverse process, and only parameter $C$ and $m$ in equation (1) were changed 
Table 8. $C$ and $m$ values at each inverse analysis step.

\begin{tabular}{lllllllll}
\hline & & Initial & $\# 1$ & $\# 2$ & $\# 3$ & $\# 4$ & $\# 5$ & $\# 6$ \\
\hline \multirow{2}{*}{ Copper wire } & $C$ & 0.017 & 0.0395 & 0.0288 & 0.0337 & 0.0314 & 0.0325 & 0.0320 \\
\multirow{2}{*}{ Aluminum wire } & $m$ & 1.09 & 1.05 & 1.09 & 1.13 & 1.10 & 1.07 & 1.04 \\
& $C$ & 0.018 & 0.0077 & 0.039 & 0.0209 & 0.0312 & 0.0254 & 0.0271 \\
& $m$ & 1.13 & 1.11 & 1.16 & 1.13 & 1.14 & 1.13 & 1.12 \\
\hline
\end{tabular}

Table 9. Updated JC parameters for copper and aluminum wires after running the inverse analysis with initial values from quasi static tests.

\begin{tabular}{lllllll}
\hline & $C_{0}$ & $m_{0}$ & $C$ & $m$ & $\Delta C(\%)$ & $\Delta m(\%)$ \\
\hline Copper & 0.017 & 1.09 & 0.032 & 1.04 & 88 & 4 \\
Aluminum & 0.018 & 1.13 & 0.027 & 1.127 & 50 & 0.2 \\
\hline
\end{tabular}

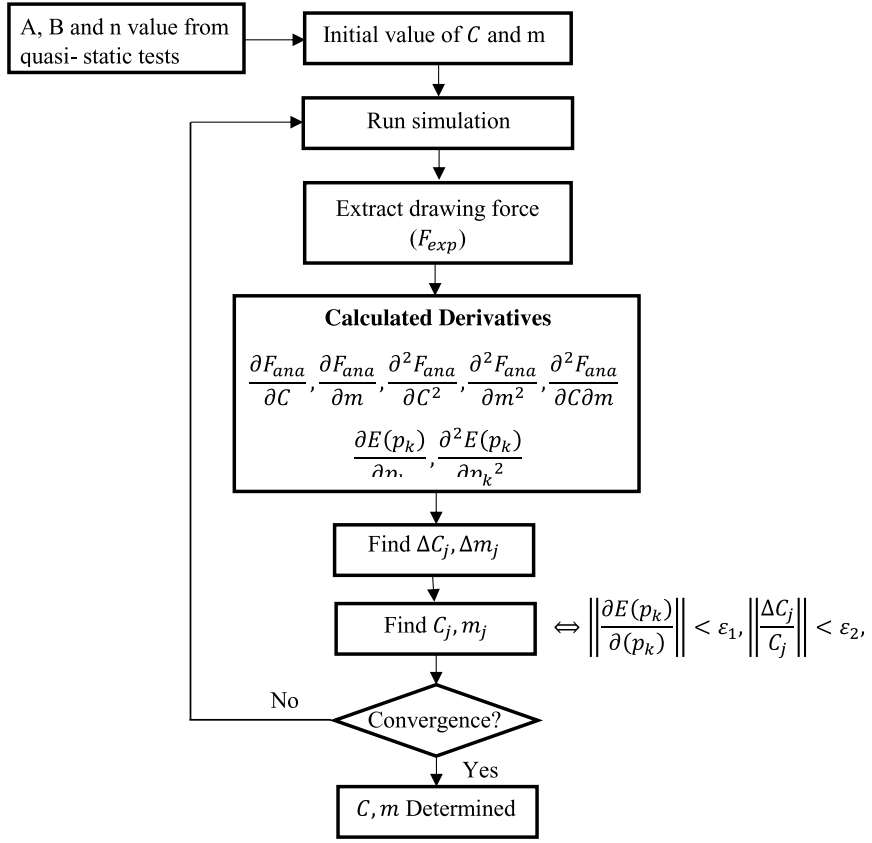

Fig. 7. Flow chart of the inverse process to determine the $C$ and $m$ parameters of the JC model.

during the inverse analysis. So the $k=2$ and equation (15) would become:

$$
\frac{\partial E(C)}{\partial C}, \frac{\partial E(m)}{\partial m}=0
$$

Using the Newton-Raphson iterative algorithm to solve the equation (16):

$$
\frac{\partial^{2} E\left(p_{k}\right)}{\partial p_{k}^{2}} \Delta p_{k j}=-\frac{\partial E\left(p_{k}\right)}{\partial p_{k}} \quad j=1,2, \ldots, q
$$

$q$ is the number of iterative to get the final $C$ and $m$ values. Taking the derivatives of objective function with respect to $C$ and $m$ :

$$
\begin{gathered}
\frac{\partial E\left(p_{k}\right)}{\partial p_{k}}=-\frac{2}{N} \sum_{i=1}^{N}\left\{\frac{\left(F_{\exp }-F_{\text {ana }}\right)}{F_{\exp }^{2}} \frac{\partial F_{\text {ana }}}{\partial p_{k}}\right\} \\
\frac{\partial^{2} E\left(p_{k}\right)}{\partial p_{k}^{2}}=-\frac{2}{N} \sum_{i=1}^{N}\left\{\frac{-1}{F_{\exp }^{2}}\left(\frac{\partial F_{\text {ana }}}{\partial p_{k}}\right)^{2}+\frac{\left(F_{\exp }-F_{\text {ana }}\right)}{F_{\exp }^{2}} \frac{\partial^{2} F_{\text {ana }}}{\partial p_{k}^{2}}\right\} .
\end{gathered}
$$

Supposing an initial value of parameter $C$ and $m$ of the JC model from quasi-static tests and literature (Tab. 3), new values for $C$ and $m$ were calculated. Simulation with the new value of $C$ and $m$ was carried out, and new drawing forces were generated. This process continues until the equation (15) was close enough to its root value, and at this point, the $C$ and $m$ were identified. The overall procedure is shown in Figure 7

The progressive $C$ and $m$ values are shown in Table 8 . The convergence criteria $\varepsilon_{1}, \varepsilon_{2}$, and $\varepsilon_{3}$ were set to $0.02,0.02$, and 0.03 , respectively.

After six iterations, the $C$ and $m$ values met the convergence criteria, and the inverse solution code stopped. Determining the new values of $C$ and $m$, the initial and updated JC parameters for copper and aluminum wires are as shown in Table 9.

As it seen in Table 9, the changing amount in $C$ values reveals that this part of the $\mathrm{JC}$ model is so vulnerable to strain rate changes and need to be altered by up to $88 \%$ of its initial value by reaching the strain rate from quasi-static to moderate strain rate.

Thermal softening parameter $(\mathrm{m})$ did not change notably since there is no considerable temperature rise in wire drawing process and it is close to isothermal process as in quasi-static tensile test. It is predictable that in hot forming processes like forging, the change in thermal softening parameter should not be overlooked. 
Table 10. Updated JC parameters for copper and aluminum wires after running the inverse analysis with different initial values.

\begin{tabular}{lllllllll}
\hline & $\mathrm{C}_{0}^{*}$ & $\mathrm{~m}_{0}^{*}$ & $C^{*}$ & $m^{*}$ & $C$ & $m$ & $\frac{\mathrm{C}-\mathrm{C}^{*}}{C}$ & $\frac{\mathrm{m}^{*} \mathrm{~m}^{*}}{m}$ \\
\hline Copper & 0.025 & 1.11 & 0.034 & 1.05 & 0.032 & 1.04 & $6 \%$ & $1 \%$ \\
Aluminum & 0.016 & 1.16 & 0.023 & 1.135 & 0.027 & 1.127 & $14 \%$ & $0.7 \%$ \\
\hline
\end{tabular}


Fig. 8. Drawing forces from experimental and simulation results with updated $\mathrm{C}$ and $\mathrm{m}$ parameter using inverse analysis for copper wire with output (a) diameter of $3.3 \mathrm{~mm}$ and (b) diameter of $3.1 \mathrm{~mm}$ and (c) aluminum wire with output diameter of $3.3 \mathrm{~mm}$.

In order to check the identifiability of the JC parameters and to validate the inverse process, a different initial value similar in literature $[7,36]$ for $C$ parameter and a different value for $m$ parameter was chosen to re-run the inverse process. The convergence criteria was set to previous inverse parameter identification. After 4 iterations initial $C_{0}^{*}$ and $m_{0}^{*}$ converged to values shown as $C^{*}$ and $m^{*}$ in Table 10.
As it seen in Table 10 the inverse approach converged almost to the same JC parameters after choosing another initial values for $C$ and $m$.

Simulation drawing results with the updated JC parameters from inverse analysis along with error content in Table 11 and Figure 8 show that the error content reduced to utmost $4 \%$ and in aluminum wire case become 0 . 
Table 11. Average drawing force from experimental and simulation results and analytical solution with updated $C$ and $m$ parameters using inverse analysis.

\begin{tabular}{|c|c|c|c|c|c|c|c|}
\hline & $D_{0}(\mathrm{~mm})$ & $D_{1}(\mathrm{~mm})$ & $V(\mathrm{~mm} / \mathrm{s})$ & $\dot{\varepsilon}\left(\mathrm{s}^{-1}\right)$ & $F_{\exp }$ & $F_{s i m}$ & Error $=\frac{F_{\exp }-F_{s i m}}{F_{\exp }} \times 100$ \\
\hline \multirow{8}{*}{ Copper wire } & \multirow{5}{*}{3.52} & \multirow{5}{*}{3.3} & 200 & 37 & 696 & 676 & 2.84 \\
\hline & & & 400 & 75 & 697 & 675 & 2.89 \\
\hline & & & 600 & 112 & 698 & 677 & 2.92 \\
\hline & & & 800 & 150 & 686 & 672 & 2.01 \\
\hline & & & 200 & 38 & 925 & 883 & 4.51 \\
\hline & \multirow[t]{3}{*}{3.52} & \multirow[t]{3}{*}{3.1} & 400 & 77 & 951 & 908 & 4.52 \\
\hline & & & 600 & 115 & 956 & 917 & 4.0 \\
\hline & & & 200 & 36 & 490 & 490 & 0 \\
\hline \multirow[t]{2}{*}{ Aluminum wire } & \multirow[t]{2}{*}{3.72} & \multirow[t]{2}{*}{3.3} & 400 & 72 & 471 & 476 & 1.06 \\
\hline & & & 600 & 108 & 470 & 461 & 1.91 \\
\hline
\end{tabular}

\section{Conclusion}

Comparison of wire drawing forces from experimental tests and simulation and analytical results showed that the JC parameters obtained from low strain rate condition did not accurately predict the material behavior at the wire drawing process with moderate strain rates. The JC parameters are valid for a limited range of strain rate and temperature and extrapolation will cause significant error. An inverse analysis was implemented to modify the initial JC parameters. The $C$ and $m$ constant of the JC model were modified after six consecutive iterations until their values matched the convergence criteria. The $C$ parameter value was changed $88 \%$ and $50 \%$ for copper and aluminum respectively. The thermal softening parameter did not changed considerably performing the inverse analysis since there is no significant temperature rise in wire drawing process comparing to quasi- static test. Simulation results with updated JC parameters showed a very good correlation with experiments, and the error content reduced to $1 \%-4 \%$ and in one case exactly matched the experiment.

\section{Nomenclature}

$A \quad$ JC constant (MPa)

$B \quad$ JC constant (MPa)

$C \quad$ JC constant

$D_{0} \quad$ Wire initial diameter $(\mathrm{mm})$

$D_{1} \quad$ Wire exit diameter $(\mathrm{mm})$

$E \quad$ Error function

$F_{\text {exp }}$ Experimental drawing force (N)

$F_{\text {ana }}$ Analytical drawing force $(\mathrm{N})$

$F_{\text {sim }}$ Simulation drawing force $(\mathrm{N})$

$l \quad$ Die forming length $(\mathrm{mm})$

$m \quad$ JC thermal softening constant

$n \quad$ JC constant

$r \quad$ Areal reduction (\%)

$T$ Temperature (K)

$V \quad$ Drawing speed $(\mathrm{mm} / \mathrm{s})$

$\begin{array}{ll}\alpha & \text { Die semi angel (degree) } \\ \varphi & \text { Redundant factor } \\ \Delta & \text { Die parameter } \\ \dot{\varepsilon} & \text { Strain rate }\left(\mathrm{s}^{-1}\right) \\ \mu & \text { Coefficient of friction } \\ \sigma & \text { Flow stress (MPa) } \\ \sigma_{d} & \text { Drawing stress (MPa) } \\ \sigma_{b} & \text { Wire back stress }(\mathrm{MPa}) \\ \sigma_{Y} & \text { Yield stress }(\mathrm{MPa})\end{array}$

\section{References}

[1] G. Vega, A. Haddi, A. Imad, Investigation of process parameters effect on the copper-wire drawing, Mater. Des. 30, 3308-3312 (2009)

[2] A. Haddi, A. Imad, G. Vega, Analysis of temperature and speed effects on the drawing stress for improving the wire drawing process, Mater. Des. 32, 4310-4315 (2011)

[3] C. Luis, J. Leon, R. Luri, Comparison between finite element method and analytical methods for studying wire drawing processes, J. Mater. Process. Technol. 164, 1218-1225 (2005)

[4] D.J. Celentano et al., Simulation and experimental validation of multiple-step wire drawing processes, Finite Elements Anal. Des. 45, 163-180 (2009)

[5] S. He et al., Strain rate effect in high-speed wire drawing process, Model. Simul. Mater. Sci. Eng. 10, 267 (2002)

[6] A.I.H. Committee, ASM handbook: mechanical testing and evaluation, Vol. 8, ASM International, 2000

[7] G.R. Johnson, W.H. Cook, A constitutive model and data for metals subjected to large strain, high strain rates and high temperatures, in Proceedings of the 7th International Symposium on Ballistics, 1983, p. 6

[8] Y. Lin, X.-M. Chen, G. Liu, A modified Johnson-Cook model for tensile behaviors of typical high-strength alloy steel, Mater. Sci. Eng. A 527, 6980-6986 (2010)

[9] G. Chen et al., Modeling of flow behavior for 7050-T7451 aluminum alloy considering microstructural evolution over a wide range of strain rates, Mech. Mater. 95, 146-157 (2016) 
[10] Y. Lin, L.-T. Li, Y.-Q. Jiang, A phenomenological constitutive model for describing thermo-viscoplastic behavior of $\mathrm{Al}-\mathrm{Zn}-\mathrm{Mg}-\mathrm{Cu}$ alloy under hot working condition, Exp. Mech. 52, 993-1002 (2012)

[11] J.Q. Tan et al., A modified Johnson-Cook model for tensile flow behaviors of 7050-T7451 aluminum alloy at high strain rates, Mater. Sci. Eng. A 631, 214-219 (2015)

[12] M. Vural, J. Caro, Experimental analysis and constitutive modeling for the newly developed 2139-T8 alloy, Mater. Sci. Eng. A 520, 56-65 (2009)

[13] H. Shin, J.-B. Kim, A phenomenological constitutive equation to describe various flow stress behaviors of materials in wide strain rate and temperature regimes. J. Eng. Mater. Technol. 132, 021009 (2010)

[14] W. Kang et al., Modified Johnson-Cook model for vehicle body crashworthiness simulation, Int. J. Veh. Des. 21, 424-435 (1999)

[15] A.H. Clausen et al., Flow and fracture characteristics of aluminium alloy AA5083-H116 as function of strain rate, temperature and triaxiality, Mater. Sci. Eng.: A. 364, 260-272 (2004)

[16] H.-Y. Li et al., A comparative study on modified Johnson Cook, modified Zerilli-Armstrong and Arrhenius-type constitutive models to predict the hot deformation behavior in $28 \mathrm{CrMnMoV}$ steel, Mater. Des. 49, 493-501 (2013)

[17] D.-N. Zhang et al., A modified Johnson-Cook model of dynamic tensile behaviors for 7075-T6 aluminum alloy, J. Alloys Compd. 619, 186-194 (2015)

[18] G. Majzoobi et al., Determination of materials parameters under dynamic loading. Part I: Experiments and simulations, Comput. Mater. Sci. 49, 192-200 (2010)

[19] T. Iwamoto, T. Yokoyama, Effects of radial inertia and end friction in specimen geometry in split Hopkinson pressure bar tests: a computational study, Mech. Mater. 51, 97-109 (2012)

[20] A. Bhaduri, Mechanical Properties and Working of Metals and Alloys. Vol. 264, Springer, 2018

[21] G.-H. Majzoobi et al., Determination of the constants of material models at high strain rates and elevated temperatures using shot impact test, J. Strain Anal. Eng. Des. 49, $342-351$ (2014)

[22] J. Ning, S.Y. Liang, Model-driven determination of JohnsonCook material constants using temperature and force measurements, Int. J. Adv. Manuf. Technol. 97, 10531060 (2018)

[23] J. Ning et al., Inverse determination of Johnson-Cook model constants of ultra-fine-grained titanium based on chip formation model and iterative gradient search, Int. J. Adv. Manuf. Technol. 99, 1131-1140 (2018)

[24] M. Agmell, A. Ahadi, J.-E. Ståhl, Identification of plasticity constants from orthogonal cutting and inverse analysis, Mech. Mater. 77, 43-51 (2014)

[25] S.V. Laakso, E. Niemi, Using FEM simulations of cutting for evaluating the performance of different johnson cook parameter sets acquired with inverse methods, Rob. Comput. Integr. Manuf. 47, 95-101 (2017)
[26] M. Grujicic et al., Modifications in the AA5083 JohnsonCook material model for use in friction stir welding computational analyses, J. Mater. Eng. Perform. 21, 2207-2217 (2012)

[27] T.G. Faurholdt, Inverse modelling of constitutive parameters for elastoplastic problems, J. Strain Anal. Eng. Des. 35, 471-478 (2000)

[28] D. Szeliga, J. Gawad, M. Pietrzyk, Inverse analysis for identification of rheological and friction models in metal forming, Comput. Methods Appl. Mech. Eng. 195, 6778-6798 (2006)

[29] X. Chen et al., On the uniqueness of measuring elastoplastic properties from indentation: the indistinguishable mystical materials, J. Mech. Phys. Solids. 55, 1618-1660 (2007)

[30] L. Meng, P. Breitkopf, G. Le Quilliec, An insight into the identifiability of material properties by instrumented indentation test using manifold approach based on $\mathrm{Ph}$ curve and imprint shape, Int. J. Solids Struct. 106, 13-26 (2017)

[31] L. Meng et al., On the study of mystical materials identified by indentation on power law and Voce hardening solids, Int. J. Mater. Form. 12, 587-602 (2019)

[32] C.K. Moy et al., Identification of the material properties of Al 2024 alloy by means of inverse analysis and indentation tests, Mater. Sci. Eng.: A 529, 119-130 (2011)

[33] T. Nakamura, T. Wang, S. Sampath, Determination of properties of graded materials by inverse analysis and instrumented indentation, Acta Mater. 48, 4293-4306 (2000)

[34] Y. Lin et al., Hot compressive deformation behavior of 7075 Al alloy under elevated temperature, J. Mater. Sci. 47, 1306-1318 (2012)

[35] H. Assadi et al., Bonding mechanism in cold gas spraying, Acta Mater. 51, 4379-4394 (2003)

[36] S. Tanimura et al., Comparison of rate-dependent constitutive models with experimental data, Int. J. Impact Eng. 69, $10(2014)$

[37] H.W. Richardson, Handbook of copper compounds and applications (CRC Press, 1997)

[38] D.W. Green, PERRY'S CHEMICAL ENGINEER'S HANDBOOK 8/E SECTION 25 MATERIALS OF CONSTRCTN (POD) (McGraw-Hill Education, 2007)

[39] R.N. Wright, Wire Drawing Technology: Process Engineering and Metallurgy (Elsevier Inc., USA, 2011)

[40] W. Evans, B. Avitzur, Measurement of friction in drawing, extrusion, and rolling, 1968

[41] B. Avitzur, Analysis of wire drawing and extrusion through conical dies of small cone angle, 1963

[42] A. Kurlov, A. Gusev, Tungsten Carbides: Structure, Properties and Application in Hardmetals (Springer, Cham-Heidelberg-NY, 2013)

[43] R. Smerd et al., High strain rate tensile testing of automotive aluminum alloy sheet, Int. J. Impact Eng. 32, 541-560 (2005)

[44] A.S. Khan, H. Liu, Variable strain rate sensitivity in an aluminum alloy: response and constitutive modeling, Int. J. Plast. 36, 1-14 (2012)

[45] H. Cho, Development of Advanced Techniques for Identification of Flow Stress and Friction Parameters for Metal Forming Analysis, in Graduate School (Ohio State University, Ohio, 2007), p. 218

Cite this article as: A.M. Aghdami, B. Davoodi, An inverse analysis to identify the Johnson-Cook constitutive model parameters for cold wire drawing process, Mechanics \& Industry 21, 527 (2020) 